\title{
Working with elderly carers of people with learning disabilities and planning for the future
}

\author{
Jane Hubert \& Sheila Hollins
}

The majority of people with learning disabilities in the UK live at home with their families, usually with their parents (Mental Health Foundation, 1996) or more commonly in later life-with one parent, usually their mother. Nowadays, people with learning disabilities live much longer than they did in the past, with the result that there is also an expanding population of elderly parents who are continuing to care for a son or daughter well into old age.

Historically, many people with learning disabilities did not survive into old age, either as a result of the physical ailments concomitant with their learning disability (such as people with Down's syndrome) or through lack of social and medical care. Over the past few decades, however, the life expectancy of people with learning disabilities has progressively improved, thus making it increasingly likely that more people with learning disabilities will outlive their parents (Walker \& Walker, 1998) and live in supported accommodation elsewhere. Better access to health care, advances in medical treatment, and improvement in social care, have all helped to increase life span, and causes of death of people with learning disabilities are increasingly the same as in the ageing population as a whole. However, the main cause of death is still (nontubercular) respiratory disease, which is not true of the general population (Hollins et al, 1998).

The increased population of older people in the community consists of two distinct groups: first, those who have been resettled in group homes or specialist units, after living for many years in an institution, and those who have lived in the community all their lives, the majority with their families; and, second, a smaller proportion (increasing as adults outlive their parents) living independently or in group homes.

\section{Closure of institutions and family involvement in resettlement}

The final closure of the old 'mental handicap' hospitals has resulted in a considerable number of ageing and 'institutionalised' men and women moving out into some degree of independent living in the community, or into staffed homes or treatment units. Many of these people require considerable health and social support if they are to live full and rewarding lives in the community.

The majority have lived in institutions for most of their lives, and their resettlement may provoke a range of difficult emotions in surviving parents and siblings, even if contact with their relative has been infrequent or even non-existent. Parents, in particular, may be very ambivalent about the move, and may prefer their son or daughter to stay in the institution that has been their home for many years, or to live in a protected, but segregated, 'village' setting.

Jane Hubert is Senior Research Fellow and Honorary Senior Lecturer in Social Anthropology in the Department of Psychiatry of Disability at St George's Hospital Medical School (Cranmer Terrace, London SW17 ORE). Her interests include social and cultural aspects of learning disabilities, and family perspectives. Sheila Hollins is Professor of Psychiatry of Learning Disability at St George's Hospital Medical School, and Honorary Consultant Psychiatrist in the South West London Community NHS Trust. One of her children has a learning disability and has made the transition to an adult life away from home. Her research interests include bereavement and learning disability. 
It is vital that professionals make every effort to involve relatives, especially surviving parents or siblings, both in the decision-making process regarding the choice of a future home, and in the actual process of transition from the institution. It is possible that active involvement in the transition of their sons and daughters to a new life 'in the community' may also help to liberate ageing parents from the enduring imprisonment of their own sense of guilt and loss.

\section{Older people with learning disabilities and their ageing family carers}

The majority of elderly people living in the community have lived there all their lives. The implications of increased longevity are highly relevant to the planning and provision of services to people with learning disabilities. There will be a considerable number of households in the community consisting of two increasingly vulnerable and perhaps isolated people: an older person with learning disabilities, and an elderly parent. Such households have a number of individual and joint needs, some of which may be conflicting (see Box 1).

The needs of older people with learning disabilities and their ageing parents, both individually and as a family unit, require coordination of services between health and social services, the voluntary and private sectors, and between generic and specialist service providers. Currently, since there is no specific policy for older people with learning disabilities, there is no one designated individual or agency that is expected to take responsibility for meeting their needs (Fitzgerald, 1998).

Box 1. Increasing numbers of elderly carers with learning disabilities

Life expectancy of people with learning disabilities is increasing

More people with learning disabilities will outlive their parents

The needs of an older person with a learning disability and an elderly parent may conflict

Cooperation between specialist learning disability and generic elderly services is required
When people with learning disabilities grow older, many of their needs are the same as for any elderly person living in the community, but professionals who work for generic services for the elderly may not consider that they have the specialised knowledge and experience to relate to people with learning disabilities. At the same time, professionals from specialist learning disability services who have been able to meet their needs in earlier years may not always feel confident when their clients become elderly and have age-related health and social support needs. Cooperation between the two services is vital to ensure that no-one slips through the net. In households where there is an elderly caring parent, also needing some care, this cooperation is even more essential. Sources of help and support need to be in place so that they can act swiftly when a crisis arises, and to provide an appropriate care package when care in the family begins to break down.

\section{Hidden population}

Although most households in which there is an ageing carer and a son or daughter with learning disabilities are known to health and/or social services, Horne (1989) stressed that both the epidemiological data and empirical evidence clearly indicate the existence of a 'hidden' population. Often, these families only come to the attention of the services when a crisis occurs, for example, when the carer or adult person with learning disabilities becomes ill, or physically incapacitated, or is suffering from dementia.

In these circumstances, conditions may have deteriorated to such an extent that the situation is irretrievable and may result in the carer and adult child being separated in an abrupt and distressing way. Efforts must be made to identify this hidden population before the situation reaches such an extreme, but this is not always straightforward. Possible sources of information include general practitioners (GPs), social workers, residential and day care facilities, health services, housing departments and housing associations, hospitals, private residential accommodation and voluntary organisations (Horne, 1989). However, many elderly people with learning disabilities and their carers still slip through the net.

Some of the parents who are not in contact at this stage will have made a conscious decision to live independently of any services, based on their knowledge of the nature of the help available at the time. Since this may have been in the 1950s or 1960s, 
they may not be fully aware of the radical changes that have taken place in social policy and service provision.

Some parents originally concealed their child's disabilities in order to avoid institutionalisation. Oswin (1994) suggests that one of the main reasons why parents kept their children at home in the past was "the threat of having to put away their children into big long-stay hospitals where they would be neglected" (p. 18). Parents may still be unaware that leaving home and going into residential care does not entail entering a large 'mental handicap' institution.

Some elderly carers may be reluctant to ask for help for other reasons, including distressing experiences in the past, such as having an uphill struggle to get help, or having requests for help rejected. Some parents also believe that asking for help is an admission of failure on their part (Walker \& Walker, 1998). They may be unwilling to call on professionals for help in case this is interpreted as meaning that they are unable to cope, and that their son or daughter might then be taken away from them.

\section{Physical health}

People with learning disabilities have all the needs that arise from the normal ageing process, and have additional ailments resulting from inadequate medical and social care. They also have significantly higher rates of physical disorders than people in the general population in association with certain genetic disorders. Thus, in Down's syndrome, hypothyroidism and vascular disease, sensory impairments and dementia are much more common (Cooper, 1998). Osteoporosis and low vitamin D levels (despite good nutrition) have been found in two recent studies of people with learning disabilities, with an increase in vertebral fractures in an older bedridden group (Center et al, 1998; Wagemans et al, 1998). Epilepsy is particularly prevalent, and the greater the severity of the learning disability, the more likely it is that epilepsy will be present. Fifty per cent of people with an IQ of less than 20 are at risk of epilepsy, compared with $0.5 \%$ of the general population (Bird, 1997). Poorly controlled epilepsy results in an increased mortality, and it remains a significant cause of death among people with severe and profound learning disabilities, because their epilepsy is often inadequately monitored and controlled. The frequency and severity of seizures may be such that good control is hard to achieve. People with learning disabilities are also at risk of long-term adverse effects of antiepileptic medication, including hypocalcaemia, which leads to loss of bone density (Deb et al, 1985; British Medical Association \& Royal Pharmaceutical Society of Great Britain, 1999).

People with learning disabilities in general do not consult their GP as frequently as the rest of the population, and uptake of services by elderly people with learning disabilities is poor (Cooper, 1998). They require a health service that is more proactive than that provided for the general population. General practitioners and other primary care staff need to be encouraged to provide the same service to people with learning disabilities as they provide to other patients in the same age group, even if that requires more time and planning. Elderly people with learning disabilities frequently have problems accessing the health care that they need, for a variety of reasons. One is that they may find it more difficult than others to identify their own health needs, partly because of their limitations in knowledge about how their body works and how it goes wrong (Dodd \& Brunker, 1998). They may also lack knowledge about the health services and how these are organised. As they grow older, as with other elderly people, mobility and access to transport can be a real impediment to getting to the doctor's surgery. People with learning disabilities living at home with their families may not have had to take the initiative for most of their lives, but when a carer becomes elderly and frail, and physically restricted, their adult children may need to access health professionals themselves, and they may not in fact know who to turn to.

General practitioners often rely on family members, who know the person with learning disabilities well, to alert them to the fact that there is something wrong - although carers themselves may also fail to recognise the signs and symptoms of illness. As parents become elderly, they may become less observant of changes in the health status of the person they have been caring for.

It is vital to identify the cause of decline in later life, and to reverse the process with the appropriate treatment wherever possible. Many common ailments in middle and later years can be improved if health and social work professionals are proactive in helping people with learning disabilities get access to the relevant services. One factor that may make this more difficult is that doctors, nurses and other health professionals are sometimes unclear about what their role should be, and are inexperienced in professional relationships with people with learning disabilities - they may consider that they do not have appropriate skills, and become demoralised in contacts of this kind (Royal College of General Practitioners, 1990). 


\section{Mental health}

Psychiatric disorders, including depression, affective disorders, anxiety disorders, delusional disorders and dementia, are more frequent among elderly people with learning disabilities than among the general elderly population. Dementia is more frequent among elderly people with learning disabilities than among the general population, and the incidence will continue to rise as longevity increases. Dementia is particularly prevalent among people with Down's syndrome, and since they age prematurely compared with others in the general population, the development of dementia can occur in middle age. Since one-third of people with severe learning disabilities have Down's syndrome, and because of increasing longevity, they contribute significantly to the numbers of people who have dementia (Cooper, 1997). It should be noted, however, that the prevalence of cognitive impairments consistent with the presence of Alzheimer's disease is not as high as would be expected from neuropathological studies (Oliver et al, 1998). Cooper (1997) has shown that dementia is also more frequent among elderly people with learning disabilities who do not have Down's syndrome than among the wider elderly population.

Dementia is generally extremely distressing for those who suffer from it, and for the people who care for them, and requires sympathetic and appropriate management. If carers are themselves elderly and frail, the situation at home may well become untenable, and extra resources in the home may no longer be adequate to meet the complex needs of the household. The problem then is how best to meet the needs of the person with learning disabilities and their elderly parent(s) - nearly always it will mean separation after a lifetime together, although there is no definitive reason why they should not move together into a facility for the elderly. There is a further issue to consider, however, if the person with dementia is only in middle age. Should they be moved into residential care with people of their own age, who may not have dementia, or into generic or specialist units for the elderly, where they may be 20-30 years younger than anyone else?

\section{Needs of older carers}

Parents who continue to care for a child with learning disabilities into his or her late middle age have their own health and social support needs as they themselves become elderly. Many carers at this stage are widowed mothers. In these circumstances, the surviving parent has lost not only a spouse, but also someone who helped in the day to day task of caring for a son or daughter with learning disabilities (Walker \& Walker, 1998). Ageing carers and their adult children have a complex set of individual and joint needs.

The caring parent may become physically or mentally infirm. Common problems include decreasing mobility and all that this implies: difficulty in getting upstairs, cleaning the house or cooking, and inability to get out of the house, to go to the shops to buy food, or to visit his or her GP.

Many family carers manage for some 40 or 50 years without any help at all from service providers, relying instead on informal sources of support. As Griffiths (1988) pointed out:

"families, friends, neighbours and other local people provide the majority of care in response to needs... This will continue to be the primary means by which people are enabled to live normal lives in community settings" (p. 5).

However, family and social networks tend to collapse, or at least become inactive, as people get older, and households in which there are elderly parents, or one surviving parent, and an ageing son or daughter with learning disabilities, are likely to become increasingly cut off from sources of informal support from family, friends and neighbours (Maggs \& Laugharne, 1996). The composition of the household also changes, not only through the possible death of a spouse, but also as other children leave home.

Informal sources of support tend to fade out at a time when carers themselves are getting increasingly frail and immobile and are needing more and more help and support, rather than less (McGrath \& Grant, 1993).

Some of those families who have not needed much or any input from the services in the past may in later years be in need of considerable help and support at home, and effective monitoring by professionals may be infrequent or absent altogether. Because a carer has managed for many years, service professionals will assume that nothing has changed, and that the situation can go on indefinitely. If there is no monitoring system to pick up gradual changes in circumstances, such situations may continue to deteriorate until there is an irreversible crisis.

It is not a simple matter to introduce services into households that have become used to a long and firmly established way of life (however deprived it may appear to others). The imposition of care packages on familiar daily routines may not always 
be welcomed, and may be perceived as an unwelcome intrusion (Baldock \& Ungerson, 1994). In this context, it is worth noting that carers do not necessarily perceive themselves as being 'stressed', and emphasise the rewards and satisfactions of caring more frequently than the stresses (Grant et al, 1998).

\section{Social isolation of elderly carers}

Parents of children with severe disabilities, and/or challenging behaviour, may become isolated from family and social networks much earlier in their lives, because of their all-pervasive caring role. In later years, their isolation may thus be even greater. A study of parents caring for young adults with severe learning disabilities and challenging behaviour at home (Hubert, 1991) revealed that even at this early stage, very few had frequent or close contact with kin outside the household, or with friends. Few of the families were part of an active kin network that provided even moral support. It appears that in circumstances such as these, kinship rights and obligations are liable to collapse under the strain of asymmetrical and necessarily unfulfilled relationships.

Such isolation, especially of mothers, can result not only from the fact that they are tied to the house, and because people tend not to want to visit such a household, but also because as their children grow up they have less and less in common with friends and relatives who have children of the same age. The successes and failures in the lives of parents such as these often have no counterpart in the daily lives of others, whose children live their own lives, have friends, go to work and get married.

The early breakdown in informal support networks in families in which there is an adult with severe disabilities, and/or challenging behaviour, has obvious implications for the planning and provision of care for such families in later years. (see Box 2).

\section{Cultural differences}

People from Black and ethnic minority groups will particularly suffer from the lack of specific policies for older people with learning disabilities. People from these groups receive less adequate services than similar families in the rest of the population (Baxter et al, 1990), partly as a result of difficulties in
Box 2. Isolation of older carers

Elderly parents are often unaware of the community support now available to adults with learning disabilities

A mutually dependent relationship may have developed according to their needs and capabilities

Parents may not ask for help for fear their son or daughter is taken into care

Elderly parents are often socially isolated

accessing services and lack of appropriate information, and partly because not enough attention is paid to different traditions and backgrounds. In some areas of Britain, appropriate community services, which respond to different cultural preferences and expectations, have been set up (Baxter et al, 1990). People from different cultural backgrounds have different expectations and preferences in the context of age and approaching death (Hogg, 1997).

Also, although professionals may sometimes assume that ethnic minority communities are closeknit and supportive, elderly people within them, especially those with learning disabilities or caring for someone with learning disabilities, may well live very isolated lives, even within their own ethnic and cultural 'community' (Zarb \& Oliver, 1993). Elderly carers of people with learning disabilities from Black and ethnic minority groups may well form part of the 'hidden' population referred to earlier.

\section{Planning for the future}

Parents who have cared for someone since they were born often wish to continue to look after them until some unspecified time in the future, and may refuse to contemplate letting them go into residential care (Richardson \& Ritchie, 1989).

In households where there is an elderly parent and an adult child who has mild or moderate learning disabilities, the nature of their relationship may have gradually changed over the years. Rather than the parent simply being the carer of their son or daughter, they may develop a mutually dependent partnership, according to their respective needs and capabilities (Walker \& Walker, 1998), and, in some cases, roles may even reverse. In these circumstances, households may continue to remain independent of services in the community, in spite of possible 
chronic situations, such as physical ill health, incontinence or even dementia of the parent. If this happens, the person with learning disabilities may well lose whatever degree of independence he or she may have had in the past.

Having a son or daughter living at home may represent a welcome continuation of family life, especially when other children leave home, and parents may rely on them for company, particularly as they become less able to get out of the house. Also, they may not be aware of other options. In order to plan future services for families, it is important to determine whether parents have continued to care for a son or daughter by choice, or because they do not consider that any alternative is appropriate or acceptable. In some cases, this might not correspond to the views of the person with learning disabilities, who may not have been enabled, or allowed, to make their preferences known.

Separation, through death or incapacity, is inevitable at some stage, probably in the relatively near future, but carers are frequently unwilling to discuss the future, or make plans for their adult child's future care. Attempts by professionals to discuss these issues are often fraught with anxiety (Todd et al, 1993). It is clear that some parents hope that their child will die before they do, so that the question of residential care does not arise (Hubert, 1991). This emphasises the importance of a forum in which both parent and child can feel safe enough to discuss the future realistically (see Box 3 ).

Where parents do succeed in making the break and supporting their son or daughter's move to a new home, their continuing involvement in care planning and in relevant day to day matters must be sensitively supported. Elderly parents may be concerned that their own intimate knowledge and understanding of their son's or daughter's needs will not be respected and taken on board. Continuity of care and sensitive communication with families is essential in order to ensure that the support needs of individuals leaving home are properly understood and recorded. New carers may perceive family members as interfering, critical and overprotective and, as a result, may withhold information, thus increasing parental concern. It is also relevant in this context that $80 \%$ of paid carers in the UK are untrained and inexperienced, and staff turnover is high.

\section{Bereavement}

What usually happens, in most households, is that unless there has been effective planning for the
Box 3. Planning for the future

Elderly parents may be less observant of health changes in their son or daughter

Comorbid medical conditions are common but easily overlooked unless actively screened for

Planning for the future should include recognising inevitable separation by death, and the need to anticipate emotional as well as practical needs

When people with learning disabilities have moved to a home of their own, sustained effort by the new carers is needed to support continuing contact with elderly parents

future, the elderly parents will die while their son or daughter is still living at home.

For almost everyone, the death of a parent causes deep and enduring grief. For people with learning disabilities, loss of a parent, especially a sole surviving parent, is not only bereavement of a parent, but also of the person who has cared for them throughout their lives, who has protected them, encouraged them, fought battles on their behalf, and with whom they have had a close, interdependent and often exclusive relationship.

The experience may be made even more difficult because people with learning disabilities are often excluded from the rituals and processes associated with dying and death - they are seldom taken to the funeral, for example, and people tend not to tell them too much, in case it 'upsets' them. Nevertheless, it is obvious that a bereaved son or daughter is well aware that life has suddenly changed, his or her mother is no longer there and probably no one talks about her. In addition, he or she will most probably be moved out of the family home and into residential care. Thus, at a time of loss, confusion and fear, a number of major life changes take place: leaving the familiar family home and moving into a strange house, living with a relatively large number of unfamiliar people, and being cared for by a rota of new carers.

Many people with learning disabilities experience a number of losses and separations from family members from early childhood onwards. It is likely that these will have been managed ineffectively, thus, losses in later life will reawaken and magnify early experiences of loss and bereavement (Harper \& Wadsworth, 1993).

It is not surprising, therefore, that the effects of bereavement (and the concomitant confusion and 
insecurity that follow a death) are particularly severe and prolonged. Hollins \& Esterhuyzen (1997), in a study of recently bereaved adults, showed that these effects may be manifested in a range of behavioural symptoms and an increase in psychopathology, including anxiety and depression.

A recent series of articles in the British Medical Journal (e.g. Parkes, 1998), relating to bereavement in adult life, has indicated a manifest need for further research on the factors that affect the duration and outcome of bereavement, and on methods by which detrimental effects can be foreseen, recognised and alleviated. A review by Cathcart (1995) showed that practical interventions and resources now exist in some areas, and others are currently being developed, in order to mitigate the distressing effects of bereavement on people with learning disabilities.

\section{Conclusion}

Planning for the future of households in which there is a person with a learning disability living with a parent or parents should ideally start long before the problems associated with age and ageing become relevant. In addition, although grief is a natural outcome of separation and loss, the further unhappiness, fear and confusion arising from traumatic events that have not been planned - or even talked about, either before, during or after they occur - may be alleviated.

Walker \& Walker (1998) recommend a number of essential components of an effective service to tackle the problems that confront elderly carers. In order that families are identified before a crisis situation arises, databases should be established of all families in which there is an elderly carer; information resources for family carers should be accessible; there should be a 'showcase' of residential care options available - flexible day and respite care provision, and emergency contact points. It is essential that regular reviews are carried out, and that plans for future care are discussed before the family situation becomes untenable.

Commissioners should ensure that older people with learning disabilities have access to mainstream primary and secondary health care, and that specialist health care services are provided to meet the needs of people who also have challenging behaviour, mental health or sensory needs, or needs relating to mobility or communication. Routine health screening is vital, in order to identify comorbid health needs and, perhaps equally important, to identify care needs - signs of deteriorating health may be indicative of a carer's decreasing capabilities, rather than of a significant decline in the health of the person for whom they care.

Health and social service professionals must be prepared to become proactive in their relationships with elderly people with learning disabilities and their carers. This involves taking responsibility at all levels, including such things as organising appropriate transport, making appointments, ensuring appointments are kept and arranging domicilary visits.

The success of these strategies will depend on close and consistent cooperation between generic services for the elderly and specialist services for people with learning disabilities, as well as coordination of services between local health and social services, and between voluntary and private service providers.

\section{References}

Baldock, J. \& Ungerson, C. (1994) Becoming Consumers of Community Care. York: Joseph Rowntree Foundation.

Baxter, C., Poonia, K., Ward, L., et al (1990) Double Discrimination: Issues and Services for People with Learning Difficulties from Black and Ethnic Minority Communities. London: King's Fund Centre/Commission for Racial Equality.

Bird, J. (1997) Epilepsy and learning disabilities. In Seminars in the Psychiatry of Learning Disabilities (ed. O. Russell), pp. 223-244. London: Gaskell.

British Medical Association \& Royal Pharmaceutical Society of Great Britain (1999) British National Formulary. London: British Medical Association \& Royal Pharmaceutical Society of Great Britain.

Cathcart, F. (1995) Death and people with learning disabilities: interventions to support clients and carers. Journal of Intellectual Disability Research ${ }_{\llcorner}$41, 331-338.

Center, J., Beange, H. \& McElduff, A. (1998) People with mental retardation have an increased prevalence of osteoporosis: a population study. American Journal of Mental Retardation, 103, 19-28.

Cooper, S-A. (1997) Psychiatric symptoms of dementia among elderly people with learning disabilities. International Journal of Geriatric Psychiatry, 12, 662-666.

- (1998) Clinical study of the effects of age on the physica health of adults with mental retardation. American Journal on Mental Retardation, 102, 582-589.

Deb, S., Cowie, V. A., Tsanaclis, et al (1985) Calcium homeostasis in mentally handicapped epileptic patients. Journal of Mental Deficiency Research, 20, 403-410.

Dodd, K. \& Brunker, J. (1998) Feeling Poorly. Brighton: Pavilion.

Fitzgerald, J. (1998) Time for Freedom? Services for Older People with Learning Difficulties. London: Centre for Policy on Ageing/Values into Action/Joseph Rowntree Foundation.

Grant, G., Ramcharan, P., Mcgrath, M., et al (1998) Rewards and gratifications among family caregivers: towards a refined model of caring and coping. Journal of Intellectual Disability Research, 42, 58-71.

Griffiths, R. (1988) Community Care: Agenda for Action. London: HMSO.

Harper, D. C. \& Wadsworth, J. S. (1993) Grief in adults with mental retardation: preliminary findings. Research in Developmental Disabilities, 14, 313-330.

Hogg, J. (1997) Intellectual disability and ageing: ecological perspectives from recent research. Journal of Intellectual Disability Research, 41, 136-143. 
Hollins, S. \& Esterhuyzen, A. (1997) Bereavement and grief in adults with learning disabilities. British Journal of Psychiatry, 170, 497-501.

—, Attard, M. T., Von Fraunhofer, N., et al (1998) Mortality in people with learning disability: risks, causes, and death certification findings in London. Developmental Medicine and Child Neurology, 40, 50-56.

Horne, M. (1989) Identifying hidden populations of older adults with mental handicap: outreach in the UK. New Zealand Journal of Developmental Disabilities, 15, 207-218.

Hubert, J. (1991) Home-Bound: Crisis in the Care of Young People with Severe Learning Difficulties: A Story of Twenty Families. London: King's Fund Centre.

Maggs, C. \& Laugharne, C. (1996) Relationships between elderly carers and the older adult with learning disabilities: an overview of the literature. Journal of Advanced Nursing, 23, 243-251

McGrath, M. \& Grant, G. (1993) The life-cycle and support networks of families with a person with a learning difficulty. Disability, Handicap and Society, 8, 25-42.

Mental Health Foundation (1996) Building Expectations: Opportunities and Services for People with a Learning Disability. Report of the Mental Health Foundation Committee of Inquiry. London: MHF.

Oliver, C., Crayton, L., Holland, A., et al (1998) A four year prospective study of age-related cognitive change in adults with Down's syndrome. Psychological Medicine, 28, 13651377

Oswin, M. (1994) Response to "Where next for research on carers?". Appendix 1. In Where Next for Research on Carers? (ed. G. Parker), pp. 17-21. Leicester: Nuffield Community Care Studies Unit.

Parkes, C. M. (1998) Coping with loss: bereavement in adult life. British Medical Journal, 316, 856-859.

Richardson, A. \& Ritchie, J. (1989) Letting Go: Dilemmas for Parents Whose Son or Daughter has a Mental Handicap. Milton Keynes: Open University Press.

Royal College of General Practitioners (1990) Primary Care for People with Mental Handicap. Occasional Paper 47. London: Royal College of General Practitioners

Todd, S., Shearn, J., Beyer, S., et al (1993) Careers in caring: the changing situations of parents caring for an offspring with learning difficulties. Irish Journal of Psychology, 14, $130-153$

Wagemans, A. M., Fiolet, J. F., Van Der Linden, E. S., et al (1998) Osteoporosis and intellectual disability: is there any relation? Journal of Intellectual Disability Research, $\mathbf{4 2}$ 370-374

Walker, C. \& Walker, A. (1998) Uncertain Futures: People with Learning Difficulties and their Ageing Family Carers. Brighton: Pavilion/Joseph Rowntree Foundation.

Zarb, G. \& Oliver, M. (1993) Ageing with a Disability: What Do They Expect After All These Years? London: University of Greenwich.

\section{Multiple choice questions}

1. Older people with Down's syndrome:

a seldom outlive their parents

b always show signs of dementia if they reach the age of 40

c may become their elderly parents' carer

$\mathrm{d}$ have all the needs that arise from the normal ageing process

e typically have one or more comorbid medical conditions.
2. Loss of skills in older people with Down's syndrome may be owing to:

a dementia

b depression

c hypothyroidism

d poor health of an elderly parent

e hearing loss.

3. The majority of people with learning disabilities:

a lived in institutions until recently

b have always lived at home

c easily make the transition from their family home to 'formal' care

d have informal sources of support that become activated as parents age

e have parents who are reluctant to let them leave home.

4. The experience of elderly parents as carers:

a is perceived by them as more stressful than satisfying

b varies for people from different cultural backgrounds

c is a welcome continuation of family life after other children have grown up and moved away

$\mathrm{d}$ is that paid staff are unable to provide good enough care for their son or daughter

e often results in the hope their child will die before them.

5. Following the death of their last surviving parent, people with learning disabilities:

a are most likely to be moved into emergency temporary care

b are seldom taken to the funeral

c do not grieve

$\mathrm{d}$ do best if not told about their parents death

e do best if they have been involved in planning and preparing for their future life long before their parent dies.

\section{MCQ answers}

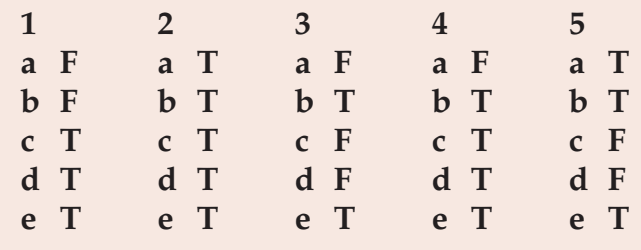

